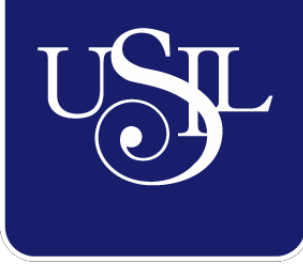

UNIVERSIDAD

SAN IGNACIO

DE LOYOLA

FACULTAD DE HUMANIDADES

Carrera de Psicología

\title{
INFLUENCIA DE LA PROCRASTINACIÓN ACADÉMICA SOBRE EL CANSANCIO EMOCIONAL EN ESTUDIANTES UNIVERSITARIOS: DIFERENCIAS SEGÚN SEXO
}

Tesis para optar el Título Profesional de Licenciado en Psicología

KRYSTEL MELANY LOPEZ CAJAVILCA

(0000-0003-3459-7194)

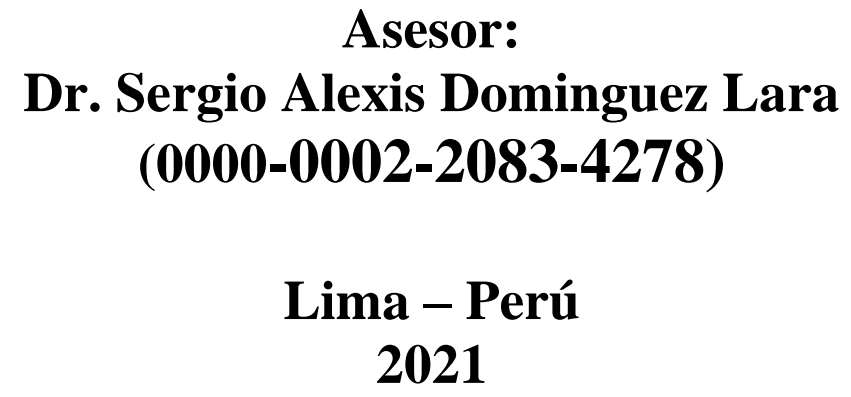




\section{Resumen}

El objetivo del presente estudio fue determinar si existen diferencias entre hombres y mujeres en cuanto a la influencia de la procrastinación académica sobre el cansancio emocional en estudiantes universitarios entre 18 y 28 años (68\% mujeres; $\left.M_{\text {edad }}=22.8\right)$ de universidades privadas. Para esto, se administró la Escala de Procrastinación Académica (EPA) y la Escala de Cansancio Emocional (ECE), y se implementó un análisis de regresión múltiple. Los resultados mostraron que las dimensiones de procrastinación académica influyen de manera positiva sobre el cansancio emocional, y que la influencia de la postergación de actividades sobre cansancio emocional fue mayor en hombres. Se discuten las implicancias teóricas y prácticas de los hallazgos, así como la necesidad de fortalecer un seguimiento de apoyo y contención que podrían afectar la conducta académica del estudiante.

Palabras clave: procrastinación académica, cansancio emocional, estudiantes universitarios, regresión múltiple. 


\begin{abstract}
The objective of the present study was to determine if there are differences between men and women in terms of the influence of academic procrastination on emotional exhaustion in university students between 18 and 28 years $\left(68 \%\right.$ women; $\left.M_{\text {age }}=22.8\right)$ from private universities. For this, the Academic Procrastination Scale (EPA) and the Emotional Tiredness Scale (ECE) were administered, and a multiple regression analysis was implemented. The results showed that the academic procrastination dimensions positively influence emotional exhaustion, and that the influence of postponement of activities on emotional exhaustion was greater in men. The theoretical and practical implications of the findings are discussed, as well as the need to strengthen a follow-up of support and containment that could affect the academic behavior of the student.
\end{abstract}

Keywords: academic procrastination, emotional exhaustion, college students, multiple regression. 


\section{Introducción}

En el entorno europeo se han mantenido los roles asociados al sexo, asignándole al hombre trabajos para el sustento económico, a diferencia de las mujeres encargadas de los cuidados y trabajos domésticos; esto trae como consecuencia mayor cansancio emocional en ellas, afectando su calidad de vida y su desarrollo personal (Aristegui, Beloki, Royo \& Silvestre, 2018). En este sentido, los roles asociados al sexo también se manifiestan en las familias monomarentales, la cual hace referencia a la mujer como la única responsable encargada del sostén del hogar en cuidados y atención a los hijos; esto trae como consecuencia el experimentar mayor cansancio emocional y dificultades para poder dormir sobretodo con la llegada del virus SARS-CoV-2 (Di Nella \& Ibáñez, 2020). Asimismo, se ha mostrado que en Lima, Perú entre el año 2001 y 2018, las estructuras familiares han cambiado, presentando un $127 \%$ en mujeres como jefas del hogar, a diferencia de los varones en un $35 \%$ según las estadísticas del INEI (Jaramillo \& Ñopo, 2020). En esta misma línea, la migración, el trabajo ejercido por las mujeres y el desarrollo personal en ellas se ha manifestado hoy en día, por lo que, el rol del hombre que se asumía como el único encargado de los gastos económicos en casa, ha cambiado al considerar que los hombres ejercen el papel doméstico y las mujeres el papel laboral (Viveros, 2010).

En el año 2020 la situación en el mundo se ha visto afectada por el virus conocido como Coronavirus SARS-CoV-2, causante de la enfermedad COVID-19 (Huerta, 2020). Desde que se inició la primera aparición del caso de un hombre que contrajo la enfermedad en Perú, en otros países sucedía lo mismo; es por ello que el 11 de marzo del 2020 la Organización Mundial de la Salud (OMS) declara la propagación del COVID-19 como pandemia, simultáneamente el presidente de la República del Perú declaró emergencia sanitaria a nivel nacional por un tiempo de 90 días (Huerta, 2020). Según se menciono anteriormente, esto mismo ocurriría en Perú con 
mayor incidencia de casos por el tema de pandemia, ya que al estar mayor tiempo en casa las demandas laborales y académicas han aumentado, y consigo el cansancio emocional en hombres y mujeres. (Llerena \& Sánchez, 2020).

Hoy en día, la pandemia ha modificado la manera de vivir y ha generado gran impacto en la salud, proyectos profesionales y seguridad (Alonzi, La Torre \& Silverstein, 2020); asimismo la expansión de la pandemia afecta el normal desenvolvimiento en instituciones educativas básicas y superiores al cambiar la modalidad de aprendizaje siendo esta de manera remota (Estrada-Araoz, Gallegos-Ramos \& Mamami-Uchasara, 2020). De igual manera, esta modalidad ha afectado tanto a docentes como estudiantes debido al uso de nuevas herramientas tecnológicas para realizar las clases (Estrada-Araoz et al, 2020); además la reacción que han tenido los estudiantes frente a esta modalidad no ha sido favorable porque han presentado una sobrecarga de trabajos, exponiéndose constantemente frente a un dispositivo móvil, laptop o computadora causando estrés, cansancio visual y fatiga (Estrada-Araoz, et al., 2020).

En vista que la salud mental de los estudiantes se ha visto afectada significativamente frente a una emergencia de salud, es necesario brindar herramientas para orientar a los que no pueden identificar y expresar de manera adecuada sus emociones frente a la pandemia (Cao, et al., 2020).

Con respecto a la teoría de la evolución, desde hace años, los antepasados del hombre moderno hicieron viajes en pequeños grupos de caza y recolección, además desarrollaron distintos trabajos y habilidades; producto de ello los hombres se encuentran centrados en objetivos y se ubican en jerarquía, mientras que las mujeres desarrollaron el talento para la palabra, sensibilidad emocional, empatía y colaboración (Buss, 1995).

Los universitarios se caracterizan por presentar aburrimiento, dificultad para administrar el tiempo e influencia de compañeros, además muestran problemas para poder equilibrar su vida social ya que se ha observado que mantienen una vida agitada con muchas 
más demandas académicas, y la manera de afrontarlo podría generar cambios positivos o negativos al momento de organizar las actividades que se les asignan, considerando las tareas diarias desde el hogar (Pardo, Perilla \& Salinas, 2014).

En la vida del estudiante, las demandas académicas generan cansancio emocional, considerado como uno de los factores estresantes que estos desarrollan (Herrera, Mohamed \& Cepero, 2016). Asimismo, se identificaron como obstáculos frecuentes el cumplimiento de tareas, adaptación de horarios y ansiedad ante exámenes (Herrera, et al., 2016). Es por ello que uno de los desafíos que enfrentan los estudiantes universitarios es el manejo de situaciones que causen estrés y demandas académicas, por lo que terminan procrastinando en algunos casos siendo limitado el tiempo de estudio (Balkis, 2013). Las consecuencias repercuten como problemas que afectan su ámbito personal, académico, laboral, social y familiar (Chan, 2011). Asimismo, la procrastinación trae consigo consecuencias académicas negativas como una calificación baja y bajo rendimiento (Dominguez-Lara, Villegas \& Centeno, 2014).

Por lo tanto, estudiantes universitarios han presentado angustia emocional por el cierre de diversos lugares y eventos sociales, menor rendimiento en la nueva modalidad de estudio y postergación de exámenes (Cao, et.al., 2020 en Xiong, et al, 2020). Las poblaciones más vulnerables a presentar síntomas relacionados al estrés son las personas menores de 40 años, estudiantes universitarios, grupo femenino, y personas que presentan enfermedades crónicas/psiquiátricas; asimismo, las mujeres y estudiantes universitarios han presentado mayor estrés en comparación con los hombres y personas ancianas (Xiong, et al., 2020). Esto ocurriría ya que las mujeres desempeñan un rol asociado al cuidado del hogar y familia, apoyo emocional a niños y ancianos y, por lo tanto, las mujeres estudiantes presentan un mayor efecto estresante durante el tiempo de pandemia (Spagnolo, Manson \& Joffe, 2020). Por lo expuesto, el sexo, roles y comportamientos que se han desarrollado socioculturalmente caracterizando al hombre y a la mujer han sido determinantes importantes de la salud y enfermedad. 
Asimismo influyen factores como la situación económica, vivir con los padres y tener un familiar que se encuentre diagnosticado con Covid-19 (Cao, et.al. 2020; Wang, et.al. 2020 en Huarcaya-Victoria, 2020). En este sentido, las exigencias desde casa hacia las mujeres universitarias han continuado, ya que se ha conservado la cultura machista dentro de las familias considerándolas como las encargadas de ejecutar los quehaceres de casa, terminando exhaustas en este proceso (Marín-Sánchez, et al. 2019).

\section{Procrastinación Académica}

Según Steel (2007) la procrastinación está presente en la parte académica, laboral y política, donde el objetivo está centrado en evitar de manera voluntaria la elaboración de una actividad o tarea. Al procrastinar, las personas presentan problemas como el estrés que afectan su salud (Stead, Shanahan \& Neufeld, 2010). Se entiende por procrastinación académica el aplazar voluntariamente tareas por dos motivos: falta de agrado y miedo a equivocarse (Steel, 2007, Dominguez-Lara, 2016b). En este sentido, la procrastinación académica se constituye por dos dimensiones como la postergación de actividades que se refiere al hecho de aplazar actividades, y la autorregulación académica, que hace referencia a las conductas que involucren planificar y cumplir las metas y acciones (Steel, 2007).

La postergación de actividades se refiere cuando el estudiante aplaza alguna actividad por otra; por otro lado, la autorregulación académica es un proceso activo y constructivo, donde el alumno establece objetivos, controla su comportamiento, su motivación y cognición; es por ello que la autorregulación académica es una acción que el estudiante realiza durante su aprendizaje (Ayala, Rodríguez, Villanueva, Hernández \& Campos, 2020).

La procrastinación en jóvenes afecta en la toma de decisiones y resolución de conflictos cuando deciden entre terminar los deberes académicos o no (Chan, 2011). Asimismo, si se mantienen conductas de procrastinación en la etapa de la adolescencia esto tendría un efecto 
negativo ya que afectaría en actividades sociales, familiares, laborales y académicos (Chan, 2011). De igual manera, la procrastinación académica puede llevar a los jóvenes a obtener un bajo rendimiento académico (Quant \& Sánchez, 2012).

Según Clariana, Cladellas, Badia y Gotzens (2011) las evidencias de los estudios relacionados a procrastinación han dado como resultado que afectaría a mediano y a largo plazo la vida académica y trae como consecuencia altos niveles de ansiedad, cansancio y estrés como también a presentar mayores enfermedades (depresión) que lo conlleven a un cansancio emocional (Pardo, Perilla \& Salinas, 2014; Tice \& Baumeister, 1997), ya que las dificultades para enfrentarse al mundo universitario implican la sobrecarga de trabajos por la falta de organización ante exámenes y prácticas, la falta de información o ambigüedad del tema y la metodología del docente (Durán, Extremera \& Rey, 2007). Es asi también que la acumulación de diversas actividades crean en el estudiante un espacio tenso y engorroso, donde surge la aparición del cansancio (Durán, Extremera \& Rey, 2007; Fernández-Martínez, Liébana-Presa \& Morán , 2017).

Se realizaron investigaciones acerca de las razones de la procrastinación, la cual dio como respuesta que los procesos cognitivos de una persona serían los factores causales (Özer, Demir \& Ferrari; 2009). Asimismo, la procrastinación se encuentra relacionada con la ansiedad por la evaluación, dificultad para tomar decisiones, la rebelión contra el control, la falta de asertividad, el miedo a las consecuencias del éxito, aversión percibida por las tareas y excesos de perfeccionismo sobre competencia (Özer, Demir \& Ferrari; 2009).

Una de las dos dimensiones centrales del síndrome del burnout es el cansancio emocional (Durán, Exremera, Rey, Fernández-Berrocal \& Montalbán, 2006); el cual es experimentado por causa de las demandas académicas (Schaufeli, Salanova, Gonzáles-Romá \& Bakker, 2002); siendo esta dimensión la más relevante para el estudio, como se explicará mas adelante. 


\section{Cansancio Emocional Académico}

Según Freudenberger (1974) el burnout fue contextualizado en el rubro laboral que se caracterizaba por presentar sentimientos y pensamientos negativos hacia los compañeros de trabajo y hacia el desenvolvimiento en el área, asimismo como sentirse agotado emocionalmente (Maslach \& Jackson, 1981). Por otro lado, el burnout en estudiantes es entendido como una consecuencia al estrés crónico relacionado al rol, actividad y contexto académico, lo cual llegaría a ser perjudicial en el desarrollo y satisfacción de los estudiantes en su vida académica (Caballero, Breso \& Gonzáles, 2015). Es así también que los estudiantes con niveles altos en burnout han experimentado cansancio con las exigencias académicas, presentan una actitud cínica hacia el estudio y se sienten poco eficaces como estudiantes (Martínez \& Marques, 2005). En esta misma línea, el burnout académico es experimentado debido a las exigencias en la universidad, provocando que el estudiante se encuentre exhausto debido al compromiso que tiene con las actividades (Schaufeli, Salanova, Gonzáles-Romá \& Bakker, 2002; Dominguez-Lara, 2016a; Ramos, Manga \& Moran, 2005).

Es asi que el cansancio emocional hace referencia a la fatiga tanto emocional como física y al desgaste energético; es decir se manifiesta como la reducción de recursos afectivos que provocan que la persona no pueda continuar con sus actividades (Barreto \& Salazar, 2021).

Por otro lado, según Martínez y Marques (2005) han considerado la dimensión de cansancio emocional como síntoma principal del burnout, ya que es la respuesta que hace referencia a los estímulos estresantes al ambiente ocupacional y una de las primeras etapas y son consideradas dimensiones centrales o "corazón del burnout" (Green, Walkey \& Taylor, 1991). Además, no se niega la existencia de las otras dos dimensiones pertenecientes al burnout, sin embargo, a nivel conceptual estas aparecerían posteriormente (Dominguez-Lara, 2016a; Dominguez-Lara, 2018). 
Durán, Extremera, Rey, Fernández-Berrocal y Montalbán (2006) refieren que el cansancio emocional y el cinismo presentan una relación positiva con el estrés y que se asocian negativamente con la autoeficacia, la percepción emocional y el compromiso que tienen académicamente los estudiantes universitarios; por este motivo el cansancio provocaría un distanciamiento emocional y cognitivo al enfrentarse al exceso de demandas académicas, que trae como consecuencia insatisfacción y dejadez (Dominguez-Lara, 2016a). Además, se vincula con la ansiedad y depresión, estrés académico, estrategias disfuncionales de regulación emocional, la autoeficacia académica y la autoestima (Dominguez-Lara, 2016a; DominguezLara \& Merino, 2019).

Según Boudreau, Sanren, Hemphill y Dobson (2004) el cansancio emocional está relacionado con componentes estresantes que incluyen largas horas de trabajo, escaso apoyo de amistades, incertidumbre por planes a futuro y poca disponibilidad de desarrollar habilidades sociales; es por ello que las consecuencias del cansancio en estudiantes resultan ser negativas ya que afectan la calidad de vida y bienestar de estos; asimismo se presenta que los rasgos de personalidad negativos se encuentran relacionados con la carga de actividades .

De igual manera, existen distintas medidas para evaluar el burnout académico, sin embargo al estudiarlo con todas las dimensiones el resultado sería una extensa evaluación; por lo que centrarse en el cansancio emocional evitará incomodidad por responder ítems similares.

\section{Diferencias De Sexo En Procrastinación Académica y Cansancio Emocional Académico}

\section{Diferencia Entre Hombres y Mujeres En Procrastinación}

Por otro lado, no existen diferencias de sexo en los niveles de procrastinación, es decir no difiere de mujeres o hombres (Özer, 2011). En la misma línea, no existen diferencias 
significativas de sexo en procrastinación ya que los más jóvenes presentan oportunidades limitadas para desarrollar patrones de trabajo (Haycock, McCarthy \& Skay, 1998).

Otros estudios han tenido como resultado que los hombres procrastinan más que las mujeres; esto difiere ya que los varones lo realizan por correr riesgos y descontrolarse, y las mujeres por miedo o temor a cometer un error y por desgano (Özer, Demir \& Ferrari, 2009, Dominguez-Lara \& Campos-Uscanga, 2017; Zhou, 2018). Por otro lado, las mujeres presentan más conductas procastinadoras en comparación con los hombres con un $65.8 \%$, siendo estos estudiantes de la Facultad de Ingeniería y arquitectura con un 15.9\% (Tice \& Baumeister, 1997, en Pardo, Perilla, \& Salinas, 2014).

Los autores comentaron que existen dos razones principales para la procrastinación académica en estudiantes: el miedo al fracaso y la aversión a las tareas (Özer, Demir \& Ferrari, 2009). El miedo al fracaso también se asocia con el perfeccionismo, la ansiedad de evaluación y la baja confianza en uno mismo y la aversión a las tareas hace referencia a la falta de motivación y frustración (Moneta, Spada \& Rost, 2007). Además, se percibió que las mujeres postergan más las tareas académicas como resultado del miedo al fracaso y la pereza a diferencia de los varones (Özer, Demir \& Ferrari, 2009).

Se da a conocer que la procrastinación se presenta en los ámbitos familiares y biológicos en mujeres. En cuanto a lo familiar, las mujeres se encuentran sujetas a presentar un control más estricto con respecto a responsabilidades académicas, la motivación que desarrollan se determina por los sentimientos de lealtad y obligación hacia sus padres y familia (Özer, Demir \& Ferrari, 2009) los hombres como resultado de la constitución hormonal; es así que las mujeres muestran mayor miedo a extraños y a los eventos desconocidos en una edad temprana, luego esto se convierte en evitación de algún objeto temible; es decir que presentar miedo al fracaso como el tener bajas notas en los cursos de la universidad provocaría que las mujeres lo eviten, a diferencia de los hombres. (Özer, Demir \& Ferrari, 2009). Por otra parte, los varones 
postergaban las tareas académicas por la toma de riesgos y rebelión contra el control (Özer, Demir \& Ferrari, 2009), por consiguiente los hombres demostraron correr más riesgos que las mujeres; como también en otros estudios se demuestra que los hombres muestran un comportamiento más agresivo que las mujeres ante las presiones psicológicas y sociales (Lippa, 2002; Özer, Demir \& Ferrari, 2009).

En este sentido, en los últimos años se ha estudiado cómo las diferencias de sexo afectan la conducta procrastinadora en relación al aprendizaje con resultados mixtos (Zhou, 2018).

\section{Diferencia Entre Hombres y Mujeres En Cansancio Emocional}

Cabe resaltar, que el sexo es importante dentro del estudio del estrés, es así que Ronen y Malach-Pines (2008) comentan que ciertos estudios han determinado que las mujeres presentan mayor cansancio emocional comparado con los varones, lo cual hace referencia a la importancia de los factores que se involucran como la cultura, entre otros. Según FernándezMartínez, Liébana-Presa y Morán (2017) las mujeres presentan mayor puntuación que los hombres al presentar estrés, siendo los hombres los que manejan de mejor manera y respuesta el estrés; ya que uno de los estresores académicos es la preocupación por los resultados, adaptación a un nuevo ambiente, exigencia de estudios e incertidumbre por el futuro (Belhumeur, Barrientos \& Retana-Salazar, 2016). Esto sucede porque los estudiantes al presentar mayores niveles de cansancio emocional obtienen bajas expectativas de acabar sus estudios satisfactoriamente y esto trae como consecuencia que no se encuentren preparados para afrontar el mundo laboral (Almeida, G.C. et al, 2016).

Estas diferencias aparecen debido a que las emociones pueden tener un valor diferencial tanto para hombres como mujeres, ya que las mujeres pueden prestar más atención a sus emociones cuando estas ocurren, compartirlas y darle significado a sus reacciones a diferencia de los hombres (Barrett, Robin, Pietromonaco \& Eyssell, 1998), considerando además las 
diferencias morfológicas del cerebro que permiten a la mujer un mayor reconocimiento de sus emociones (Kret \& De Gelder, 2012). Asimismo, en el ámbito académico, las mujeres solicitan apoyo social para enfrentarse al estrés y presentan mayor preocupación por agradar a adultos, en especial a padres y profesores (búsqueda de apoyo), por el otro lado los hombres buscan estrategias relacionada al cumplimiento de alguna acción enfocado a la solución de problemas (cognitivo) (Cabanach, Fariña, Freire, Gonzáles \& Ferradás, 2013).

\section{Integración entre procrastinación y cansancio emocional}

Tomando en cuenta lo mencionado, las situaciones como cambio de horarios, traslados, exámenes, exigencia de estudios, etc., han demostrado ser variables que generan estrés y preocupación. En este sentido, las mujeres son las que gestionan equilibradamente su tiempo con sus actividades académicas (Castro, 2020).

El estudio del sexo ha desarrollado un papel muy importante dentro de estudios respecto

a estrés y cansancio emocional (Dominguez-Lara, Fernández-Arata, Manrique-Millones, Alarcón-Parco \& Díaz-Peñaloza, 2017). En este mismo contexto, las diferencias entre hombres y mujeres podrían ser causa de la cultura, edad, carga de trabajo, puesto del trabajo, entre otras (Ronen \& Malach-Pines, 2008).

La teoría de la esperanza académica es una teoría motivacional que explica la manera en que los alumnos utilizan su pensamiento: cruzado, agente y motivación, para conseguir sus objetivos académicos (Snyder, 2002). El pensamiento cruzado hace referencia a formas o métodos de pensar para cumplir con las metas educativas; el pensamiento agente se refiere a la motivación por parte del alumno por su esfuerzo; y el pensamiento motivacional se refiere a que las metas se encuentran instrínsicamente relacionadas con la planificación (Snyder, 2002). En este mismo contexto, de acuerdo con las bases de teoría motivacional como la terapia de la esperanza, las razones de la procrastinación académica y el cansancio emocional académico se 
deben a factores como el autocontrol y la autoeficacia, esto quiere decir que el autocontrol se encuentra relacionado con la impulsividad del alumno al empezar demasiadas tareas que pueden terminar por abandonar otras (Mohammadipour \& Rahmati, 2016); por el otro lado la autoeficacia hace referencia al bajo grado de confianza del alumno debido al fracaso, que conlleva a retirarse de logros académicos como la finalización de tareas (Mohammadipour \& Rahmati, 2016); es por ello que los universitarios que procrastinan experimentan odio al hacer la tarea terminando por posponerlo, por lo que tienen poca esperanza al no sentirse capaces de cumplir con sus tareas ocasionándoles cansancio emocional (Seo, 2008).

En síntesis, es importante precisar las investigaciones que se encuentren relacionadas con el objetivo del trabajo expuesto; ya que va a permitir conocer si la variable sexo es relevante en la influencia de la procrastinación académica sobre el cansacio emocional.

\section{Antecedentes}

Dominguez-Lara, Prada-Chapoñan y Moreta-Herrera (2019) realizaron una investigación que ha considerado como objetivo principal determinar la existencia de diferencias entre hombres y mujeres en cuanto a la influencia de las dimensiones de personalidad sobre la procrastinación académica. La muestra estuvo constituida por 986 alumnos, el $69.8 \%$ mujeres entre 16 y 40 años de edad, el $93.8 \%$ solteros y $27.6 \%$ actualmente trabajando. Se usó el cuestionario "Escala de Procrastinación Académica (EPA)" que fue creado por Busko (1998) adaptado por Dominguez-Lara, Villegas y Centeno (2014), y el Big Five Inventory-15P (BFI-15P) validado por Dominguez-Lara y Merino-Soto (2018) que presenta 5 dimensiones: extraversión, amabilidad, responsabilidad, neuroticismo y apertura. Los resultados evidencian que existe una influencia positiva y significativa de responsabilidad sobre la autorregulación académica $\left(\beta_{\text {hombres }}=.538 ; \mathrm{p}<.001 ; \beta_{\text {mujeres }}=.653 ; \mathrm{p}<.001\right)$ y una influencia positiva y significativa de neuroticismo sobre postergación de actividades ( $\beta_{\text {hombres }}$ 
$\left.=.068 ; \mathrm{p}=.415 ; \beta_{\text {mujeres }}=.245 ; \mathrm{p}<.001\right)$. Concluyeron que existe una presencia significativa del neuroticismo y baja responsabilidad, considerandose como una factor de riesgo para las mujeres.

Balkis (2013) realizó una investigación con el objetivo de describir la relación entre procrastinación académica y burnout en Turquía. La muestra conformada fue de un total de 323 de estudiantes (216 mujeres) entre los 17 a 31 años. Se usaron dos instrumentos: Aitken Procrastination Inventory (API) creado por Aitken (1982) y Maslach Burnout InventoryStudent Survey (MBSS) creado por Maslach, C. y Jackson, S. E. (1981). que presenta tres dimensiones: cansancio emocional, cinismo y eficacia académica. Los resultados indicaron una correlación significativa positiva entre procrastinación académica y cansancio emocional. $(r=.324, \mathrm{p}<.01)$. Concluyeron que los estudiantes que presenten altos niveles de dilación y cansancio son más propensos a presentar problemas que afecten su rendimiento académico.

Tekkurşun Demir, Halıcı y Ötkan (2017) realizaron una investigación que ha considerado como objetivo la relación entre procrastinación académica y niveles de burnout en estudiantes de la facultad de Ciencias del deporte en la universidad Gazi en Ankara. La muestra estuvo constituida por 406 estudiantes, de los cuales 150 fueron mujeres y 256 fueron hombres. Se usó el formulario del estudiante de inventario de desgaste de Maslach (MBI-SF) creado por Schaufeli et. al. (2002) y trasladado al idioma Turco. Para medir los niveles de procrastinación académica en estudiantes se utilizó el instrumento de Escala de Procrastinación académica de Cakici (2003). Los resultados indicaron las diferencias entre hombres y mujeres respecto a la procrastinación no fueron significativas $(t=-1.424 ; p=.155)$; como también respecto al cansancio emocional $(t=-1.444 ; p=.150)$. Concluyeron que que los niveles de cansancio y procrastinación académica no muestran diferencia significativa en términos de sexo.

Ocal (2016) realizó una investigación donde se examinó el rol del cansancio, la autoeficacia académica y el éxito académico en la predicción de la procrastinación y la 
satisfacción con la vida universitaria entre los estudiantes de escuelas deportivas. La muestra estuvo constituida por 224 estudiantes (64.3\% hombres) entre las edades 18 y 30 años. Se usó el cuestionario de cansancio versión turca del MBI-SS realizado por Çapri, Gündüz y Gökçakan (2011), y para evaluar la procrastinación se usó la escala de procrastinación de Tuckman (TPS) (1991). Los resultados evidencian una correlación directa y significativa entre procrastinación y cansancio $(r=.311 ; p<0.05)$. Concluyeron que todas las correlaciones entre predictores y procrastinación fueron estadísticamente significativas.

Castro (2020) realizó una investigación que ha considerado como objetivo establecer la relación entre cansancio emocional y la procrastinación académica en estudiantes universitarios. La muestra estuvo conformada por 206 alumnos, el $79.6 \%$ eran mujeres y el 20.4\% varones entre los 16 a 34 años. Se usó el cuestionario Escala de Cansancio Emocional versión de Fontana (2011) y validada por Dominguez-Lara (2014), y la Escala de Procrastinación Académica validada por Dominguez-Lara, Villegas y Centeno (2014). Los resultados que no existen diferencias significativas en la dimensión cansancio emocional y postergación de actividades respecto en función al sexo $(t=-1.69 ; p=.092)$; sin embargo la variable cansancio emocional $(t=2.34 ; p=.020)$ y la dimensión autorregulación académica $(t$ $=2.44 ; p=.015)$ mostraron diferencias significativas en una magnitud pequeña donde las mujeres puntúan más alto. Concluyeron que no existe una relación significativa entre cansancio emocional y las dimensiones de la procrastinación académica.

Dominguez-Lara (2017) realizó una investigación que ha considerado como objetivo reportar la prevalencia de procrastinación académica en estudiantes de psicología de dos universidades privadas. La muestra lo conformaban 517 alumnos, los cuales el $76.2 \%$ eran mujeres con edades comprendidas entre 16 y 56 años $(M=23.16)$. Se usó el cuestionario de Escala de Procrastinación Académica adaptada para universitarios limeños (Dominguez et al., 2014). Los resultados demuestran que no existen diferencias significativas en hombres y 
mujeres con la variable procrastinación académica $(t=1.270, p=.205)$. Concluyó que la proporción elevada de mujeres puede que haya influido en las diferencias encontradas según sexo.

Fernández-Martínez, Liébana-Presa y Morán (2017) realizaron una investigación que ha considerado como objetivo evaluar la relación del sentido de coherencia con el cansancio emocional. La muestra estuvo conformada por 960 estudiantes universitarios ( $81 \%$ mujeres) con edades comprendidas entre 18 y 49 años. Se usó la versión adaptada de Escala de Cansancio Emocional (ECE) de Ramos, Manga y Morán (2005). Los resultados demuestran que se encontraron diferencias significativas entre hombres y mujeres con la variable cansancio emocional $(t=-10.134, p=<.000)$. Concluyeron que las mujeres puntúan más alto que los hombres en cansancio emocional.

Wang, Jiang y Song (2016) realizaron una investigación que ha considerado como objetivo explorar el papel mediador del cansancio emocional académico entre la motivación del logro y la procrastinación académica en estudiantes de pregrado. La muestra lo conformaban 223 estudiantes universitarios de pregrado, de los cuales 142 fueron mujeres y 81 fueron hombres. Se utilizó un cuestionario sobre la postergación del aprendizaje de los universitarios (APC), el Cuestionario de agotamiento académico de los estudiantes universitarios (Edición revisada de MBI-GS) y la Escala de motivación por el logro (AMS). Los resultados demuestran que existe una correlación significativa entre la procrastinación académica y el agotamiento académico de los estudiantes universitarios $(r=.337 p<.001)$ Concluyeron que el agotamiento académico juega un papel completamente mediador en la procrastinación académica.

Mohammadipour y Rahmati (2016). realizaron una investigación que ha considerado como objetivo predecir el cansancio académico de los estudiantes de secundaria basados en el ajuste social, la procrastinación académica y la esperanza académica. La muestra estuvo 
conformada por 350 estudiantes femeninas de una escuela de Bojnourd. Se usó la Escala de evaluación de la procrastinación (PAS) de Solomon y Rothblum (1984) y la escala Maslach Burnout Inventory-Student Survey (MBSS). Los resultados mostraron correlaciones estadísticamente significativas entre los puntajes de agotamiento y procrastinación académica $(r=.228 ; p<.001)$. Concluyeron que los estudiantes que postergan y presentan agotamiento debido al odio hacia la realización de la tarea, tienden a posponerla. Es por ello que tienen poca esperanza y ajuste social porque sienten que son incapaces de realizar lo que le asignan.

\section{Objetivo}

Comparar la influencia de las dimensiones de procrastinación académica sobre el cansancio emocional entre hombres y mujeres.

\section{Justificación}

La importancia de este trabajo se deriva a desarrollar nuevos aportes con estas variables. Se han presentado distintos trabajos de investigación que se relacionan a cansancio emocional y procrastinación académica; sin embargo, no se han realizado investigaciones que incluyan al sexo como una variable relevante en jóvenes universitarios.

Se pretende demostrar la importancia de conocer qué tanto difiere la influencia de la procrastinación académica en el cansancio emocional en hombres y mujeres. Por ese motivo, esta investigación será una primera aproximación a la necesidad de enfatizar el nivel de influencia para así demostrar que esto impacta de manera significativa. Asimismo, esta investigación se orienta a ser una colaboración como generación de conocimiento dentro del campo de psicología. 
Es así que, las diferencias de sexo influyen también en la personalidad como lo demuestra (Zhou, 2018) al mencionar que hombres y mujeres difieren en escrupulosidad, neuroticismo y amabilidad; por otro lado también se descubrió que fue un moderador en la relación entre personalidad y procrastinación, los cuales son elementos importantes que requieren un estudio base.

\section{Hipótesis}

Como hipótesis general de trabajo, se plantea que la influencia de las dimensiones de la procrastinación académica sobre cansancio emocional es significativa (H1) y la influencia de las dimensiones de la procrastinación académica sobre el cansancio emocional es mayor en las mujeres (H2). En cuanto a las hipótesis especificas se plantea lo siguiente:

-H1.1: La postergación de actividades influye de manera positiva sobre el cansancio emocional.

-H1.2: La autorregulación académica influye de manera negativa sobre cansancio emocional.

-H2.1: La influencia de la autorregulación académica sobre el cansancio emocional es mayor en las mujeres.

-H2.2: La influencia de la postergación de actividades sobre el cansancio emocional es mayor mujeres. 


\section{Método}

\section{Tipo y diseño de la investigación}

La investigación se basará en una estrategia asociativa de diseño comparativo para comparar la influencia de una variable sobre otra, teniendo como objetivo comparar la influencia de la variable criterio (Cansancio Emocional) a partir de la variable predictora (dimensiones de la Procrastinación Académica) entre hombres y mujeres (Ato, Lopez, \& Benavente, 2013).

\section{Participantes}

Se contó con una muestra no probabilística con la participación de alumnos de una universidad privada de Lima Metropolitana. Para el cálculo del tamaño de la muestra, se utilizó el sofware $G^{*}$ Power 3.1.7 (Faul, Erdfelder, Lang \& Buchner, 2007), y como insumo se consideró una magnitud del efecto esperada de .344 , con un poder estadistico de potencia .95 , y con base a ello se determinó que la muestra mínima necesaria es de 83 universitarios.

Los criterios de inclusión fueron: ser estudiantes universitarios peruanos entre el $3^{\circ} \mathrm{y}$ $8^{\circ}$ ciclo durante el semestre 2020-II. En esta misma línea, los universitarios accedieron de manera voluntaria a formar parte de la investigación. Los criterios de exclusión fueron: encontrarse estudiando fuera de una universidad de Lima, ser egresado de una universidad de Lima, encontrarse estudiando por segunda vez otra carrera y ser estudiante de traslado externo.

La muestra estuvo compuesta por 338 universitarios peruanos (68\% mujeres), los cuales tienen la siguiente descripción: $68.0 \%$ fueron mujeres. El rango de edad estuvo entre 18 y 28 años $(M=22.8 ; \mathrm{DE}=2.30)$; la mayoría de los participantes procedía de una universidad privada y cursando entre $3 \mathrm{er}(13.6 \%)$, 4to $(6.5 \%)$, 5to $(12.7 \%), 6$ to $(8.0 \%), 7 \mathrm{mo}(18.0 \%)$ y $8 \mathrm{vo}$ (41.1\%) ciclo. Asimismo, se eliminaron los datos de 63 participantes atendiendo a los criterios de inclusión y exclusión planteados. 


\section{Instrumentos}

Cabe resaltar que para la confiabilidad de las dimensiones de cada instrumento se utilizó el coeficiente alfa de cronbach, la cual se calculó con la muestra de este estudio. Para la recolección de datos, el instrumento que se utilizó para medir la variable Procrastinación Académica fue la Escala de Procrastinación Académica (Busko, 1998) adaptado al Perú en universitarios de Lima (Dominguez-Lara, Villegas \& Centeno, 2014) con 12 ítems de cinco alternativas de respuesta desde Nunca hasta Siempre. Asimismo, presenta dos dimensiones: Autorregulación académica con 9 ítems $(\alpha=.70)$ y Postergación de actividades con 3 ítems $(\alpha=.664)$.

Asimismo, se utilizó el Cuestionario de Cansancio Emocional adaptado en estudiantes universitarios peruanos de Lima Metropolitana (Dominguez-Lara, 2014) con 10 items de respuesta desde Raras veces hasta Siempre considerando los 12 últimos meses como estudiante $(\alpha=.934)$.

\section{Procedimiento}

Para la recolección de datos, se inició solicitando el permiso a la universidad para poder evaluar a los universitarios; al recibir la aprobación, se procedió a enviar el formulario con las encuestas por medio de correos institucionales. Sin embargo, la recolección de la tasa de respuestas no fue alta. En vista de esa situación, se cambió la estrategia de recolección de información a los entornos vinculados con redes sociales tardando un promedio de cuatro semanas.

En el formulario que se envío, se encuentra descrito el consentimiento informado donde se especifica que la participación es voluntaria, anónima y la confidencialidad de sus respuestas, de la misma forma, se menciona el objetivo de la investigación, la duración (10 
minutos), los instrumentos y un correo para que se puedan comunicar en caso requieran mayor información o para conocer los resultados de la investigación.

\section{Análisis de datos}

Para el análisis de datos se utilizó el programa estadístico Jamovi version 1.2 (The Jamovi Project, 2020); en primera instancia se procedió a evaluar el análisis de confiabilidad a partir del coeficiente alfa. Específicamente, con una muestra mayor de 300, la dimensión que presenta 6 ítems o menos se consideran valores desde .70 como favorable, .75 moderado, .80 bueno y .85 excelente; y para la dimensión que presenta entre 7 a 11 ítems se consideran valores desde .75 como favorable, .80 como moderado, .85 como bueno y .90 como excelente (Ponterotto \& Ruckdeschel, 2007).

Asimismo, con la base de datos se procedió a analizar el estadístico descriptivo para cada variable tanto en hombres como en mujeres.

Los resultados se interpretaron a apartir de la magnitud del efecto (ME) siendo $r>.20$ considerado como significativo. Previo al análisis de regresión lineal se tomaron en cuenta algunos supuestos estadísticos; en primer lugar, la normalidad, para poder analizar la distribución de las variables (curtosis) se tomaron en cuenta valores aceptables menores que 3; seguidamente, la linealidad, se valoró explorando la asociación entre las variables a partir de la correlación de Pearson entre las dimensiones de procrastinación académica sobre cansancio emocional; asimismo, la independencia de errores, se analizó con la magnitud del estadístico de Durbin-Watson, considerando como aceptable los valores entre 1.5 y 2.5 ; finalmente, la información sobre la multicolineadidad se obtuvo con los indicadores de tolerancia al considerar aceptables valores mayores que .10, y el factor de inflación de varianza (FIV) al considerar aceptables valores menores que 10 (Vilà Baños, Torrado-Fonseca \& ReguantÁlvarez, 2019). Seguidamente, se procedió a analizar un análisis de regresión lineal múltiple para el contraste de hipótesis específicas, es decir, la comparación de la influencia de la variable 
procrastinación académica sobre cansancio emocional en hombres y mujeres. Se consideró un $\mathrm{R}^{2}$ como insignificante (valores menores de .04), bajo (entre .04 y .25), moderado (entre $.25 \mathrm{y}$ .64) y fuerte (mayores que .64); de igual forma, para la beta estandarizada se consideró un $\beta$ insignificante (valores menores a .20), bajo (entre .20 y .50), moderado (entre .50 y .80) y fuerte (mayores que .80) (Ferguson, 2009). 


\section{Resultados}

\section{Análisis descriptivo}

En el análisis descriptivo, los valores obtenidos en las tres dimensiones superan a la potencial media teórica de Procrastinación académica $\left(\mathrm{M}_{\mathrm{teórica}}=9\right)$, Autorregulación académica $\left(\mathrm{M}_{\text {teórica }}=27\right)$ y Cansancio Emocional $\left(\mathrm{M}_{\text {teórica }}=30\right)($ Tabla 1$)$. En lo que respecta al coeficiente de confiabilidad se obtuvieron valores que se encuentran por debajo del valor aceptado con una diferencia mínima en las dimensiones de Procrastinación académica como la postergación de actividades $(\alpha=.664)$ y autorregulación académica $(\alpha=.70)$, y en Cansancio Emocional $(\alpha=.934)$.

\section{Tabla 1}

Análisis descriptivo de las variables de estudio en hombres y mujeres

\begin{tabular}{llllllllllll}
\hline \multicolumn{1}{c}{ Hombres } & \multicolumn{1}{c}{ Mujeres } \\
\hline$M$ & $D E$ & $g 1$ & $g 2$ & $\alpha$ & $M$ & $D E$ & $g 1$ & $g 2$ & $\alpha$ \\
& & & & & & & & & & &
\end{tabular}

Procrastinación académica

$\begin{array}{lllllllllll}\text { PA } & 8.97 & 1.98 & -.492 & .699 & .687 & 9.67 & 2.02 & -.502 & 2.03 & .643 \\ & & & & & & & & & & \\ \text { AA } & 31.5 & 3.87 & -.613 & .304 & .610 & 32.4 & 4.52 & -.528 & 2.08 & .728\end{array}$

\section{Cansancio Emocional}

$$
\begin{array}{lllllllllll}
\mathrm{CE} & 31.4 & 8.68 & -.595 & -.772 & .952 & 35.0 & 7.39 & -.842 & 1.26 & .918
\end{array}
$$

Nota: $M=$ Media $; D E=$ desviación estándar; $g 1$ = coeficiente de asimetría de Fisher; $g 2$ = coeficiente de curtosis de Fisher $; A A=$ Auotrregulación académica PA = Postergación de actividades $;$ CE = Cansancio emocional; $\alpha$ = Alfa de Cronbach.

Respecto al análisis de la relación lineal de la variables, se obtuvo una correlación baja entre cansancio emocional y postergación de actividades $(r=.322 ; p<.001)$; por otro lado se 
obtuvo que no existe una correlación entre cansancio emocional y autorregulación académica $(r=.001 ; p=.992)$ (Tabla 2). En cuanto al análisis principal, se encontró una influencia conjunta estadísticamente significativa $(\mathrm{F}[2,335]=20.3 ; p<.001)$ y de magnitud baja $\left(R^{2}=\right.$ .103) de procrastinación académica sobre cansancio emocional. Específicamente, mientras que la postergación de actividades influye de forma significativa sobre cansancio emocional y presenta un nivel bajo $(\beta>.20)$ por lo tanto la hipótesis 1.1 recibe respaldo, la autorregulación académica no influye de forma significativa $(\beta<.20)$ por lo tanto la hipótesis 1.2 no recibe respaldo. En consecuencia, la hipótesis general 1 recibe un respaldo parcial (Tabla $3)$.

\section{Tabla 2}

Matriz de correlaciones

\begin{tabular}{ccc}
\hline & & $C E$ \\
\hline PA & $\mathrm{r}$ & .322 \\
& $\mathrm{p}$ & .001 \\
$\mathrm{NA}$ & $\mathrm{r}$ & \\
& $\mathrm{p}$ & .001 \\
& & .992 \\
\hline
\end{tabular}

Nota: $r$ = coeficiente de Pearson; $p$ = significancia estadística

\section{Tabla 3}

Análisis de regresión lineal múltiple

\begin{tabular}{cccc}
\hline & $t$ & $p$ & $\beta$ \\
\hline PA & 6.37 & .001 & .335 \\
AA & -1.24 & .215 & -.065 \\
$\mathrm{R}^{2}$ & .103 & &
\end{tabular}

Nota: $t$ Estadístico de Student $; p=$ Significancia Estadística $; \beta=$ Coeficiente de Beta Estandarizado $; R^{2}=$ Estadístico Ajustado

La hipótesis general 2 plantea que la influencia de las dimensiones de procrastinación académica sobre la dimensión cansancio emocional es mayor en mujeres, la hipótesis 2.1 hace referencia a que la influencia de la autorregulación académica sobre el cansancio emocional 
es mayor en las mujeres; y la hipótesis 2.2 especifíca que la influencia de la postergación de actividades sobre el cansancio emocional es mayor mujeres.

Para el grupo de hombres, la evaluación del supuesto de la normalidad obtuvo un valor favorable menor que 3 (Tabla 1); con respecto a la linealidad se obtuvo una correlación insignificante entre cansancio emocional y autorregulación académica $(r=-.026 ; p=.791)$; sin embargo se obtuvo una correlación baja entre cansancio emocional y postergación de actividades $(r=.382 ; p<.001)$; la independencia de errores se valoró con la magnitud del estadístico de Durbin-Watson donde se obtuvo como resultado que fueron aceptables (1.39); finalmente al analizar la multicolinealidad se obtuvo un factor de inflación de varianza (FIV) aceptable $(1.02<10)$ y un indicador de tolerancia aceptable $(.983>.10)$.

En cuanto al análisis de regresión en hombres, se encontró una influencia conjunta estadísticamente significativa $(\mathrm{F}[2,105]=9.39 ; p<.001)$ y de magnitud baja $\left(R^{2}=.136\right)$ de las dimensiones de procrastinación académica. Específicamente, solo la dimensión postergación de actividades influyó de forma significativa, aunque a un nivel bajo $\left(\beta_{h}>.20\right)$, mientras que en la autorregulación académica no $\left(\beta_{h}<.20\right)$ (Tabla 4).

Para el grupo de mujeres, la evaluación del supuesto de la normalidad alcanzó un valor favorable menor que 3 (Tabla 1); con respecto a la linealidad se obtuvo una correlación baja entre cansancio emocional y postergación de actividades $(r=-.256 ; p<.0001)$; por otro lado se obtuvo una correlación insignificante entre cansancio emocional y autorregulación académica $(r=-.016 ; p=.804)$; la independencia de errores se valoró con la magnitud del estadístico de Durbin-Watson donde se obtuvo como resultado que fueron aceptables (1.64). Finalmente, al analizar la multicolinealidad se obtuvo un factor de inflación de varianza (FIV) aceptable $(1.04<10)$ y un indicador de tolerancia aceptable $(.957>.10)$.

En cuanto al análisis de regresión en mujeres, se encontró una influencia conjunta estadísticamente significativa $(\mathrm{F}[2,227]=8.62 ; p<.001)$ y de magnitud baja $\left(R^{2}=.062\right)$ de las 
dimensiones de procrastinación académica. Específicamente, solo la dimensión de postergación de actividades influye de forma significativa aunque a un nivel bajo $\left(\beta_{m}>.20\right)$, mientras que en la autorregulación académica no $\left(\beta_{m}<.20\right)$ (Tabla 4).

\section{Tabla 4}

Análisis de regresión lineal múltiple en hombres y mujeres

\begin{tabular}{ccccccc}
\hline & Hombres & \multicolumn{5}{c}{ Mujeres } \\
\hline & $t$ & $p$ & $\beta$ & $t$ & $p$ & $\beta$ \\
\hline AA & -0.84 & .399 & -.076 & -1.11 & .268 & -.072 \\
PA & 4.32 & .001 & .392 & 4.14 & .001 & .271 \\
$\mathrm{R}^{2}$ & .136 & & & .062 & &
\end{tabular}

$\overline{\text { Nota: } t} t=$ Estadístico de Student $; p=$ Significancia Estadística $; \beta=$ Coeficiente de Beta Estandarizado $; R^{2}=$ Estadístico Ajustado.

En ese sentido, se encuentra que la hipótesis 2.1 no obtuvo respaldo ya que la magnitud de la influencia de la autorregulación académica sobre el cansancio emocional es insignificante en ambos grupos $\left(\beta_{h}=-.076 ; \beta_{m}=-.072\right)$. Asimismo, la hipótesis 2.2 no obtuvo respaldo ya que la magnitud de la influencia de la postergación de actividades sobre el cansancio emocional difiere entre los grupos al obtener un valor mayor en hombres $\left(\beta_{h}=.3920\right.$; $\left.\beta_{m}=.271\right)$. En consecuencia, la hipótesis general 2 no recibe respaldo. 


\section{Discusión}

Los estudiantes universitarios constantemente enfrentan diversas demandas académicas. Esta situación involucra que algunos estudiantes procrastinen, y a su vez les genere cansancio emocional; asimismo la manera de percibirlo influye tanto en hombres como mujeres, sobretodo en tiempos de pandemia donde la modalidad es remota. Por lo tanto, el objetivo principal de esta investigación es comparar la influencia de la procrastinación académica sobre el cansancio emocional en hombres y mujeres.

Para la interpretación de hallazgos, la primera hipótesis plantea que existe una influencia significativa de las dimensiones de la procrastinación académica sobre cansancio emocional. Se encontró que en la primera hipótesis específica (1.1), la postergación de actividades influye sobre el cansancio emocional. Por consiguiente, el estudiante que aplaza sus actividades puede llegar a experimentar una situación estresante afectándolo de manera emocional y cognitivamente. Por tanto, cuando el estudiante posterga hace que se acumulen las actividades académicas por un inadecuado manejo del tiempo, por el desconocimiento de algunas tareas que el docente asigna y también por la metodología que el profesor emplea con sus alumnos (Durán, Extremera \& Rey, 2007). Por lo que ha traído como resultado que las personas que postergan sus actividades se vean afectados no solo a mediano plazo sino que a futuro y esto traería consigo enfermedades (depresión) que tendrían como consecuencia experimentar cansancio emocional (Clariana, Cladellas, Badia \& Gotzens, 2011). Por el contrario, se encontró que en la segunda hipótesis específica (1.2) la autorregulación de actividades no influye sobre el cansancio emocional. Esto quiere decir que el estudiante que proyecta sus metas no experimentará necesariamente una respuesta negativa, tanto a nivel emocional como cognitivo (Dominguez-Lara, Prada-Chapoñan y Moreta-Herrera, 2019). De la misma forma, la planificación de acciones o metas no se vería afectada por alguna preocupación a corto, mediano y largo plazo, ya que si el estudiante organiza adecuadamente 
sus metas o logros a cumplir sin sobreexigirse o dejarse llevar por experiencias negativas sobre el cumplimiento de actividades, no experimentará la sobrecarga de tareas de la universidad. Por consiguiente, trae como desenlace que el estudiante se cuestione adecuadamente acerca de su percepción con su nivel académico y que esto no afecte su bienestar físico y emocional (Boudreau, Sanren, Hemphill \& Dobson, 2004).

De la misma forma, la segunda hipótesis refiere que la influencia de las dimensiones de la procrastinación académica sobre el cansancio emocional es mayor en las mujeres. Se encontró que en la primera hipótesis específica (2.1) la autorregulación académica no influye sobre el cansancio emocional en ninguno de los grupos. Por consiguiente, quiere decir que los varones buscan estrategias o nuevos planes para poder realizar sus actividades académicas enfocándose en brindar una solución (cognitivo); en el caso de las mujeres, biológicamente son más expresivas aceptando sus emociones, sin embargo los planes o metas no se verían afectados, ya que ellas buscan el equilibrio (emocional y cognitivo) al gestionar adecuadamente su tiempo con las actividades académicas sin que estas afecten su rendimiento (Cabanach, Fariña, Freire, Gonzáles \& Ferradás, 2013). De igual importancia, la segunda hipótesis específica (2.2) no se asocia con los resultados obtenidos. Por consiguiente, la postergación de actividades no influye sobre el cansancio emocional en las mujeres. Por lo que la postergación influye sobre el cansancio emocional más en hombres que en mujeres. Esto puede explicarse porque los hombres postergan más sus actividades ya que les gusta correr riesgos y descontrolarse, llevándolos a experimentar mayor cansancio emocional (Özer, Demir \& Ferrari, 2009, Dominguez-Lara \& Campos-Uscanga, 2017; Zhou, 2018). Por otro lado, las mujeres también postergan sus actividades por miedo a fracasar o fallar a sus padres o amigos conduciéndolas a experimentar situaciones estresantes (Özer, Demir \& Ferrari, 2009).

En la primera hipótesis, específicamente la 1.1, los resultados encontrados coinciden con otros estudios en que la procrastinación académica se asocia con el cansancio emocional. 
Por ejemplo, Balkis (2013) reportó que la procrastinación académica y cansancio emocional presentan una correlación significativa positiva, esto se debe a que los alumnos que procrastinan no cumplen con las tareas a tiempo, y esto trae como consecuencia desgaste de energía y por ende cansancio emocional. Por otro lado, los resultados encontrados con la influencia de la autorregulación académica sobre el cansancio emocional no recibieron respaldo en la hipótesis 1.2; sin embargo la dimensión de autorregulación académica presenta una relación positiva y significativa con la dimensión de responsabilidad (Dominguez-Lara, Prada-Chapoñan \& Moreta-Herrera, 2019). Esto quiere decir que la dimensión responsabilidad se refiere a la capacidad de planificar y controlar las actividades, la cual abarca parte del significado de la autorregulación académica. En esta misma línea, esto se debe a que según la teoría motivacional, influyen dos razones por las que el alumno procrastina y presenta cansancio emocional, como el autocontrol y la autoeficacia, lo que conllevaría a que la persona presente impulsividad al querer culminar todas sus actividades; sin embargo, al no experimentarla, el alumno relaciona su autorregulación académica controlando de manera adecuada el presentar impulsividad (Mohammadipour \& Rahmati, 2016).

En la segunda hipótesis general, específicamente la 2.1 no coincide con los demás estudios revisados al determinar que la influencia de la autorregulación académica sobre el cansancio emocional es mayor en mujeres. En este mismo contexto, se ha considerado la situación actual por la que se encuentra atravesando el país por el virus conocido como Coronavirus SARS-CoV-2 y los roles que desempeñan ambos sexos; es así que esta situación ha generado cambios positivos por parte de los estudiantes universitarios tanto hombres como mujeres, ya que la planificación de sus metas, al menos con la muestra de este estudio, no se habría visto afectada por la pandemia y tampoco por su sexo, por lo que no ha tenido como consecuencia experimentar algún efecto estresante. Por otro lado, específicamente la hipótesis 2.2 no recibe respaldo al determinar que la influencia de la postergación de actividades sobre 
el cansancio emocional sería mayor en mujeres. Por ejemplo, Castro (2020) determina que no existe una asociación entre sexo y postergación académica y tampoco entre sexo y cansancio emocional porque los grupos difieren entre sí; al contrario en este estudio sí se encontró una asociación entre sexo, postergación y cansancio emocional, en la medida en que la influencia de postergación de actividades sobre cansancio emocional en el grupo de hombres es más grande. En este mismo contexto, las diferencias entre hombres y mujeres en la influencia de la postergación académica sobre el cansancio emocional podrían ser causa de los roles de sexo, ya que en ciertas situaciones se ha mantenido la visión de que las mujeres son las encargadas del área doméstica, sobrecargándose de tareas y generándoles mayor cansancio emocional y los varones encargados de la parte económica; sin embargo, esto ha cambiado en las familias, donde las mujeres también laboran y se desarrollan profesionalmente y los hombres se encargan de los quehaceres en casa, cuidado de niños, entre otros (Viveros, 2010); por consiguiente posterga sus actividades generándole mayor cansancio emocional que las mujeres . En este mismo contexo, la carga de trabajo como el puesto que desempeñan, también es considerada como causa, porque la medida o experiencia en que estas se desarrollan difiere en ambos sexos.

En cuanto a las implicancias prácticas, los hallazgos muestran la relevancia que tiene la postergación de actividades, especialmente en el grupo de varones, por lo que a partir de estos aspectos se podría promover sistemas de tutorías en donde el profesor brinde un seguimiento destinado al apoyo y contención de los alumnos que presentan dificultades y problemas relacionados a los hábitos de estudio, dificultad para expresarse oralmente como en escrito y superar temores que surgen de ellos mismos; dado que de acuerdo a los resultados los hombres son más propensos a la procrastinación en el entorno académico, por ende es más probable que presentan mayor experiencia de cansancio emocional (Gómez-Collado, 2012). 
En la presente investigación puede considerarse como una fortaleza el estudio de la influencia de un constructo sobre otro, ya que no se ha realizado ninguna investigación que aborde la diferencia de sexo en cuanto a la influencia de la procrastinación académica sobre el cansancio emocional, siendo este tema novedoso; y que se realizó en un contexto diferente (pandemia), ya que actualmente los trabajos, clases y exámenes de la universidad no se realizan de manera presencial, por lo que en casa las exigencias y demandas con respecto a roles y responsabilidades están asociadas directamente con los aspectos analizados en este estudio.

De acuerdo con la investigación, se encontró como limitación la falta de antecedentes que involucren las tres variables juntas. Asimismo, se trabajó con una muestra de universitarios pertenecientes a instituciones educativas superiores privadas de la ciudad de Lima; si bien es cierto la investigación ha proporcionado información relevante sobre la influencia de las dimensiones de procrastinación académica sobre cansancio emocional, no se podría generalizar los resultados, por lo que es necesario que sea estudiado en otras ciudades del país y regiones.

En conclusión a partir de los resultados obtenidos se ha evidenciado que las dimensiones de procrastinación académica influyen de manera parcial siendo la dimensión de postergación de actividades la que influye de manera positiva sobre cansancio emocional y la dimensión de autorregulación académica no influye sobre el cansancio emocional; asimismo se evidenció que la influencia de la dimensión autorregulación académica no influye sobre el cansancio emocional en ambos grupos; sin embargo la postergación de actividades influye más en hombres que en mujeres. En esta misma linea, estos hallazgos aportarían al conocimiento dentro del campo de psicología ya que se consideraría como primera investigación que estudia estas tres variables, especialmente porque se realizó en situación de pandemia donde los roles según sexo difieren a comparación de otros hallazgos en donde la 
mujer, ante demandas de actividades académicas tiende a procrastinar más y por ende a presentar mayor cansancio emocional.

Se recomienda para futuras investigaciones realizar una evaluación de la integración de variables como la edad, número de hijos y ciclo en el que se encuentran los estudiantes para analizar cuánto influyen; ya que la conducta procrastinadora es mayor en la adolescencia y baja progresivamente en la adultez (Rodríguez \& Clariana, 2017); asimismo se sugiere que se considere una cantidad de personas de diferentes segmentos poblacionales como los centros privados y públicos fuera de Lima (Dominguez-Lara, Prada-Chapoñan \& Moreta-Herrera, 2019). 


\section{Referencias}

Aitken, M. E. (1982). A personality profile of the college student procrastinator. (Doctoral dissertation, University of Pittsburgh, 1982). Dissertation Abstracts International, 4, 722. Recuperado de https://elibrary.ru/item.asp?id=7357318

Almeida, G. de C., Souza, H. R. de, Almeida, P. C. de, Almeida, B. de C., \& Almeida, G. H. (2016). The prevalence of burnout syndrome in medical students. Archives of Clinical Psychiatry (São Paulo), 43(1), 6-10. http://doi:10.1590/0101-60830000000072

Alonzi, S., La Torre, A. y W.Silverstein, M. (2020). The psychological impact of preexisting mental and physical health conditions during the COVID-19 Pandemic. Psychological Trauma: Theory, Research, Practice, and Policy, 12(1), 236-238. http://doi: $10.1037 / \operatorname{tra} 0000840$

Álvarez, Ó. (2010). Procrastinación general y académica en una muestra de estudiantes de secundaria de Lima metropolitana. Persona, 13, 159-177. https://www.redalyc.org/pdf/1471/147118212009.pdf

Aristegui, I., Beloki, U., Royo, R. \& Silvestre, M. (2018). Cuidado, valores y género: la distribución de roles familiares en el imaginario colectivo de la sociedad española. Inguruak, (65), 90-108. Recuperado de http://inguruak.eus/index.php/inguruak/article/view/133

Ato, M., López, J. \& Benavente, A. (2013). Un sistema de clasificación de los diseños de investigación en psicología. Anales de Psicología, 29(3), 1038-1059. doi: http://doi.org/10.6018/analesps.29.3.178511

Ayala, A., Rodríguez, R., Villanueva, W., Hernández, M. \& Campos, M. (2020). La procrastinación académica: teorías, elementos y modelos. Revista Muro de la Investigación, 5(2), 40-52. https://doi.org/10.17162/rmi.v5i2.1324

Balkis, M. (2013). The relationship between academic procrastination and student's burnout. Hacettepe University Journal of Education, 28(1), 68-78. Recuperado de http://efdergi.hacettepe.edu.tr/yonetim/icerik/makaleler/127-published.pdf

Barrett, L. F., Robin, L., Pietromonaco, P. R., \& Eyssell, K. M. (1998). Are Women the "More Emotional" Sex? Evidence From Emotional Experiences in Social Context. Cognition \& Emotion, 12(4), 555-578. https://doi.org/10.1080/026999398379565

Barreto, D. \& Salazar, H.(2021). Agotamiento Emocional en estudiantes universitarios del área $\begin{array}{lllll}\text { de la salud. } \quad \text { Universidad } & \text { y }\end{array}$ https://doi.org/10.22267/rus.212301.211 
Belhumeur, S., Barrientos, A. \& Retana-Salazar, A. (2016). Niveles de estrés de la población estudiantil en Costa Rica. Diferencias en función de las variables nivel socioeconómico, rendimiento académico, nivel académico y zona geográfica. Psychology, Society, \& Education, 8(1), 13-22. Recuperado de http://ojs.ual.es/ojs/index.php/psye/article/view/457

Boudreau, D., Santen, S.A., Hemphill, R.R. \& Dobson, J. (2004) Burnout in medical students: examining the prevalence and predisposing factors during the four years of medical school. Annals of Emergency Medicine, 44(4), 75-76. https://doi.org/10.1016/j.annemergmed.2004.07.248

Busko, D. A. (1998). Causes and consequences of perfectionism and procrastination: A structural equation model (Tesis de maestros inédita). University of Guelph, Ontario, Canadá.

Buss, D. M. (1995). Psychological sex differences: Origins through sexual selection. American Psychologist, 50(3), 164-168. https://doi:10.1037/0003-066x.50.3.164

Cabanach, R., Fariña, F., Freire, C., Gonzáles, P. \& Ferradás, M. (2013). Diferencias en el afrontamiento del estrés en estudiantes universitarios hombres y mujeres. European Journal of Education and Psychology, 6(1), 19-32. https://doi.org/10.30552/ejep.v6i1.89

Caballero, C, Breso, E. y Gonzáles-Gutiérrez, O. (2015). Burnout en estudiantes universitarios. $\begin{array}{llll}\text { Psicología desde el } & \text { Caribe, } & \text { 32(3), }\end{array}$ http://dx.doi.org/10.14482/psdc.32.3.6217

Cakici, D. C. (2003). An examination of the general procrastination behavior and academic procrastination behavior in high-school and university students (Tesis de maestría inedita). Ankara University, Ankara.

Cao, W., Fang, Z., Hou, G., Han, M., Xu, X., Dong, J. \& Zheng, J. (2020). The psychological impact of the COVID-19 epidemic on college students in China. Psychiatry Research, 287, 112934. http://10.1016/j.psychres.2020.112934

Çapri, B., Gündüz, B. \& Gökçakan, Z. (2011). Maslach tükenmişlik envanteri-öğrenci formu (mteöf) "nun Türkçee ye uyarlaması: Geçerlik ve güvenirlik çalışması. Çukurova Üniversitesi Eğitim Fakültesi Dergisi, 40(1), 134-147. Recuperado de https://app.trdizin.gov.tr/publication/paper/detail/TVRJeE1EVTRPQT09

Castro, V. (2020). Cansancio emocional y procrastinación académica en estudiantes de una universidad privada de Lima Metropolitana (Tesis de bachiller). Recuperada de http://200.37.102.150/handle/USIL/10148 
Chan, L. (2011). Procrastinación académica como predictor en el rendimiento académico en jóvenes de educación superior. Temática Psicológica: Revista especializada de los programas académicos de Doctorado y Maestría en Psicología, 7(1), 53-62. https://doi.org/10.33539/tematpsicol.2011.n7.807

Clariana, M., Cladellas, R., Badía, M. \& Gotzens, C. (2011). La influencia del género en variables de la personalidad que condicionan el aprendizaje: inteligencia emocional y procrastinación académica. Revista Electrónica Interuniversitaria de Formación del Profesorado, 14(3), 87- 96. Recuperado de http://www.aufop.com, el 09.07.13.

Di Nella, D. \& Ibáñez, V. (2020). Causas y consecuencias de la Pandemia COVID-19. De la inmovilidad de la humanidad a la circulación desconcentrada de personas. Derechos En Acción, 15(15), 415-485. https://doi.org/10.24215/25251678e407

Dominguez-Lara, S. (2013). Análisis psicométrico de la Escala de Cansancio Emocional en estudiantes de una universidad privada. Revista Digital de Investigación en Docencia Universitaria, 7(1), 45-55. http://doi:10.19083/ridu.7.186

Dominguez-Lara, S. (2014). Escala de Cansancio Emocional: Estructura factorial y validez de los ítems en estudiantes de una universidad privada. Avances en Psicología, 21(1), 8997. https://doi.org/10.33539/avpsicol.2014.v22n1.275

Dominguez-Lara, S. (2016a). Agotamiento emocional académico en estudiantes universitarios: ¿Cuánto influyen las estrategias cognitivas de regulación emocional. Educación Médica, 19(2), 96-103. https://doi.org/10.1016/j.edumed.2016.11.010

Dominguez-Lara, S. (2016b). Datos normativos de la Escala de Procrastinación Académica en estudiantes de psicología de Lima. Evaluar, 16(1), 20-30. https://doi.org/10.35670/1667-4545.v16.n1.15715

Dominguez-Lara, S. (2017). Prevalencia de procrastinación académica en estudiantes universitarios de Lima Metropolitana y su relación con variables demográficas. Revista de Psicología, 7(1), 81-95. Recuperado de https://revistas.ucsp.edu.pe/index.php/psicologia/article/view/49

Dominguez-Lara, S., \& Campos-Uscanga, Y. (2017). Influencia de la satisfacción con los estudios sobre la procrastinación académica en estudiantes de psicología: un estudio preliminar. Liberabit, 23(1), 123-135. https://doi.org/10.24265/liberabit.2017.v23n1.09

Dominguez-Lara, S., Fernández-Arata, M., Manrique-Millones, D., Alarcón-Parco, D., \& Díaz-Peñaloza, M. (2017). Datos normativos de una escala de agotamiento emocional 
académico en estudiantes universitarios de psicología de Lima (Perú). Educación Médica, 19(3), 246-255. https://doi.org/10.1016/j.edumed.2017.09.002

Dominguez-Lara, S., Villegas, G. \& Centeno, S. B. (2014). Procrastinación académica: validación de una escala en una muestra de estudiantes de una universidad privada. Liberabit, 20(2), 293-304. Recuperado de http://www.scielo.org.pe/pdf/liber/v20n2/a10v20n2

Dominguez-Lara, S., \& Merino-Soto, C. (2018). Dos versiones breves del Big Five Inventory en universitarios peruanos: BFI-15p y BFI-10p. Liberabit, 24(1), 81-96. https://doi.org/10.24265/liberabit.2018.v24n1.06

Dominguez-Lara, S., Prada-Chapoñan, R., \& Moreta-Herrera, R. (2019). Gender differences in the influence of personality on academic procrastination in Peruvian college students. Acta Colombiana de Psicología, 22(2), 137-147. http://dx.doi.org/10.14718/acp.2019.22.2.7

Durán, A., Extremera, N. \& Rey, L. (2007). Inteligencia emocional y su relación con los niveles de burnout, engagement y estrés en estudiantes universitarios. Revista de Educación, 342 , 239-256. Recuperado de https://dialnet.unirioja.es/servlet/articulo?codigo=2253635

Durán, A., Extremera, N., Rey, L., Fernández-Berrocal, P., \& Montalbán, F. M. (2006). Predicting academic burnout and engagement in educational settings: Assessing the incremental validity of perceived emotional intelligence beyond perceived stress and general self-efficacy. Psicothema, 18, 158-164. Recuperado de http://www.psicothema.com/psicothema.asp?id=3292

Estrada-Araoz, E. G., Gallegos-Ramos, N. A., Mamani-Uchasara, H. J., \& Huaypar-Loayza, K. H. (2020). Actitud de los estudiantes universitarios frente a la educación virtual en tiempos de la pandemia de COVID-19. Revista Brasileira de Educação do Campo, 5, 1-19. https://doi.org/10.20873/uft.rbec.e10237

Faul, F., Erdfelder, E., Lang, A.-G., \& Buchner, A. (2007). G*Power 3: A flexible statistical power analysis program for the social, behavioral, and biomedical sciences. Behavior Research Methods, 39, 175-191. Recuperado de http://www.psychologie.hhu.de/fileadmin/redaktion/Fakultaeten/MathematischNaturwissenschaftliche_Fakultaet/Psychologie/AAP/gpower/GPower3-BRMPaper.pdf 
Ferguson, C. (2009). An effect size primer: a guide for clinicians and researchers. Professional Psychology: Research and Practice, 40(5), 532-538. https://doi.org/10.1037/a0015808

Fernández-Martínez, E., Liébana-Presa, C. Y Morán, C. (2017). Relación entre el sentido de coherencia y el cansancio emocional en estudiantes universitarios. Psychology, Society, \& Education, 9(3), 393-403. http://dx.doi.org/10.25115/psye.v9i3.861

Fontana, S. (2011). Estudio preliminar de las propiedades psicométricas de la escala de desgate emocional para estudiantes universitarios. Revista Argentina de Ciencias del Comportamiento, 3(2), 44-48. https://doi.org/10.32348/1852.4206.v3.n2.5227

Freudenberger, H. J. (1974). Staff burn-out. Journal of Social Issues, 30(1), 159-165. https://doi.org/10.1111/j.1540-4560.1974.tb00706.x

Gómez-Collado, M. (2012). La percepción de los estudiantes sobre el programa de tutoría académica. Convergencia, 19,(58), 209-233. Recuperado de http://www.scielo.org.mx/scielo.php?script=sci_arttext\&pid=S140514352012000100009

Green, D. E., Walkey, F. H., \& Taylor, A. J. (1991). The three-factor structure of the Maslach Burnout Inventory: A multicultural, multinational confirmatory study. Journal of Social Behavior \& Personality, 6(3), 453-472. Recuperado de https://psycnet.apa.org/record/1992-11360-001

Haycock, L. A., McCarthy, P., \& Skay, C. L. (1998). Procrastination in College Students: The Role of Self-Efficacy and Anxiety. Journal of Counseling \& Development, 76(3), 317-324. https://doi:10.1002/j.1556-6676.1998.tb02548.x

Herrera, L., Mohamed, L. y Cepero, S. (2016). Cansancio emocional en estudiantes universitarios. Revista de Educaçăo e Humanidades, 9, 173-191. Recuperado de https://dialnet.unirioja.es/servlet/articulo?codigo=5429381

Huarcaya-Victoria, J. (2020). Consideraciones sobre la salud mental en la pandemia de COVID-19. Revista Peruana Medicina Experimental y Salud Publica, 37(2), 327-34. https://doi.org/10.17843/rpmesp.2020.372.5419

Huerta, E. (7 de Abril de 2020). Coronavirus: Esta es la cronología del COVID-19 en el Perú y el mundo. Radio Programas del Perú, p. 1.

Jaramillo, M. \& Ñopo, H. (2020). Impactos de la epidemia del coronavirus en el trabajo de las mujeres en el Perú. ( $1^{\mathrm{a} e d}$.). Lima: Grade.

Kret, M. \& De Gelder, B. (2012). A review on sex differences in processing emotional signals. Neuropsychology, 50, 1211-1221. https://doi.org/10.3389/fpsyg.2018.01072 
Marín-Sánchez, A., Álvarez-Sierra, D., González, O., Lucas-Martin, A., Sellés-Sánchez, A., Rudilla, F., Enrich, E., Colobran, R. \& Pujol-Borrell, R. (2019). Regulation of TSHR Expression in the Thyroid and Thymus May Contribute to TSHR Tolerance Failure in Graves’ Disease Patients via Two Distinct Mechanisms. Frontiers in Immunology, 10, 1695. https://doi:10.3389/fimmu.2019.01695

Martínez, I. \& Marques, A. (2005). Burnout en estudiantes universitarios de España y Portugal y su relación con variables académicas. Aletheia, (21) 21-30. Recuperado de https://www.redalyc.org/pdf/1150/115013476003.pdf

Maslach, C., \& Jackson, S. E. (1981). The Measurement of Experienced Burnout. Journal of Organizational Behaviour, 2(2), 99-113. https://10.1002/ job.4030020205

Mohammadipour, M., Rahmati, F. (2016). The predictive role of social adjustment, academic procrastination and academic hope in the high school students' academic burnout. Interdisciplinary Journal of Education, 1(1), 35-45. Recuperado de http://iaseidje.ir/article-1-31-en.pdf

Moneta, G. B., Spada, M. M., \& Rost, F. M. (2007). Approaches to studying when preparing for final exams as a function of coping strategies. Personality and Individual Differences, 43(1), 191-202. https://doi.org/10.1016/j.paid.2006.12.002

Lippa, R. A. (2002). Gender, nature, and nurture. London: Erlbaum

Llerena, R. \& Sánchez, C. (2020). Emergencia, gestión, vulnerabilidad y respuestas frente al impacto de la pandemia COVID-19 en el Perú. Scielo Prepints, (1),1-16. http://doi.org/10.1590/SciELOPreprints.94

Ocal, K. (2016). Predictors of academic procrastination and university life satisfaction among Turkish sport schools students. Academic Journal, 11(7), 482-490. Recuperado de https://eric.ed.gov/?id=EJ1099974

Özer, B. U. (2011). A cross sectional study on procrastination: who procrastinate more? International Conference on Education Research and Innovation, 18,34-37. Recuperado de https://www.semanticscholar.org/paper/A-Cross-Sectional-Study-onProcrastination\%3A-Who\%C3\%96zer/50fc3cbc75c77de3e103e1c912014958e97df131

Özer, B. U., Demir, A., \& Ferrari, J. R. (2009). Exploring academic procrastination among Turkish students: possible gender differences in prevalence and reasons. Journal of Social Psychology, 149(2), 241-257. https://doi:10.3200/socp.149.2.241-257 
Pardo, D. Perilla, L. Y Salinas, C. (2014). Relación entre procrastinación académica y ansiedad-rasgo en estudiantes de psicología. Cuadernos Hispanoamericanos de Psicología, 14(1), 31-44. https://doi.org/10.18270/chps.v14i1.1343

Ponterotto, J. \& Ruckdeschel, D. (2007). An Overview of Coefficient Alpha and a Reliability Matrix for Estimating Adequacy of Internal Consistency Coefficients with Psychological Research Measures. Perceptual and Motor Skills, 105(3), 9971014. doi:10.2466/pms.105.3.997-1014

Quant, M. y Sánchez, A. (2012). Procrastinación, procrastinación académica: concepto e implicaciones. Revista Vanguardia Psicológica Clínica Teórica y Práctica, 3(1), 4455. Recuperado de https://dialnet.unirioja.es/servlet/articulo?codigo=4815146

Ramos, F. Manga, D. y Moran, C. (Febrero, 2005). Escala de Cansancio Emocional (ECE) para estudiantes universitarios: Propiedades psicométricas y asociación. Trabajo presentado en Interpsiquis. España. Recuperado de http://psiqu.com/1-2898 Rodríguez, A., \& Clariana, M. (2017). Procrastinación en estudiantes universitarios: su relación con la edad y el curso académico. Revista Colombiana de Psicología, 26(1), 45-60. doi: 10.15446/rcp.v26n1.53572

Ronen, S. \& Malach-Pines, A. (2008). Gender differences in engineers' burnout. Equal $\begin{array}{llll}\text { Opportunities } & \text { International, } & \text { 677- }\end{array}$ 691. https://doi.org/10.1108/02610150810916749

Seo, E. H. (2008). Self-efficacy as a mediator in the relationship between self-oriented perfectionism and academic procrastination. Social Behavior and Personality, 36(6), 753-764. https://doi.org/10.2224/sbp.2008.36.6.753

Schaufeli, W. B., Salanova, M., González-Romá, V., \& Bakker, A. (2002). The measurement of engagement and burnout: A two sample confirmatory factor Analytic Approach. Journal of Happiness Studies, 3(1), 71-92. https://doi.org/10.1023/A:1015630930326

Snyder, C. R. (2002). Hope Theory: Rainbows in the Mind. Psychological Inquiry , 13 (4), 249-275. https://doi.org/10.1207/S15327965PLI1304_01

Solomon, L. J. \& Rothblum, E. D. (1984). Academic procrastination: Frequency and cognitivebehavioral correlates. Journal of Counseling Psychology, 31, 503509. https://doi.org/10.1037/0022-0167.31.4.503

Spagnolo, P. A., Manson, J. E., \& Joffe, H. (2020). Sex and Gender Differences in Health: What the COVID-19 Pandemic Can Teach Us. Annals of Internal Medicine, 173(5), 385-386. https://doi:10.7326/m20-1941 
Stead R., Shanahan J., \& Neufeld J. (2010). "I'll go to therapy, eventually": Procrastination, stress and mental health. Personality and Individual Differences, 49(3), 175180. https://doi.org/10.1016/j.paid.2010.03.028

Steel, P. (2007) The nature of procrastination: a meta-analytic and theoretical review of quintessential self-regulatory failure. Psychological Bulletin, 133(1), 65-94. https://doi:10.1037/0033-2909.133.1.65

Tekkurşun Demir, G., Halıcı, A., \& Ötkan, C. Ç. (2017). Examination of burnout levels and academic procrastination of university students. SHS Web of Conferences, 37, 01042. https://doi:10.1051/shsconf/20173701042.

The jamovi project (2020). jamovi. (Version 1.2) [Computer Software]. Retrieved from https://www.jamovi.org.

Tice, D. M., \& Baumeister, R. F. (1997). Longitudinal Study of Procrastination, Performance, Stress, and Health: The Costs and Benefits of Dawdling. Psychological Science, 8(6), 454-458. https://doi:10.1111/j.1467-9280.1997.tb00460.x

Tuckman, B. W. (1991). The development and concurrent validity of the procrastination scale. Educational Psychological Measurement, 51(2), 473-480. https://doi.org/10.1177/0013164491512022

Vilà Baños, R., Torrado-Fonseca, M., y Reguant-Álvarez, M. (2019). Análisis de regresión lineal múltiple con SPSS: un ejemplo práctico. REIRE Revista d'Innovació i Recerca en Educació, 12(2), 1-10. http:// doi.org/10.1344/reire2019.12.222704

Viveros, E. (2010). Roles, patriarcado y dinámica interna familiar: reflexiones útiles para Latinoamérica. Revista Virtual Universidad Católica del Norte, (31), 388-406. Recuperado de https://www.redalyc.org/pdf/1942/194214587017.pdf

Wang, C., Pan, R.,Tan, Y., Xu, L., Ho, C.S. \& Ho, R.C. (2020). Immediate Psychological Responses and Associated Factors during the Initial Stage of the 2019 Coronavirus Disease (COVID-19) Epidemic among the General Population in China. International Journal of Environmental Research and Public Health, 17, 1729. https://doi.org/10.3390/ijerph17051729

Wang, D., Jiang, Y. \& Song, L. (2016). Relationship between Achievement Motivation and Academic Procrastination in Undergraduate Students: Mediation Effect of Academic Burnout. Advances in psychology, 6(7), 779-789. http://dx.doi.org/10.12677/ ap.2016.67102

Xiong, J., Lipsitz, O., Nasri, F., Lui, L. M. W., Gill, H., Phan, L., Chen-Li, D, Iacobucci, M., Ho, R., Majeed, A. \& McIntyre, R. S. (2020). Impact of COVID-19 Pandemic on 
Mental Health in the General Population: A Systematic Review. Journal of Affective Disorder, 277, 55-64. https://doi:10.1016/j.jad.2020.08.001

Zhou, M. (2018). Gender differences in procrastination: The role of personality traits. Current Psychology, 39(3), 1445-1453. https://doi:10.1007/s12144-018-9851-5 


\section{Anexos \\ Formulario de Consentimiento Informado}

Estimado/a estudiante:

La investigación titulada "Influencia de la procrastinación académica sobre el cansancio emocional en estudiantes universitarios: diferencias según sexo" es conducida por Krystel López, bachiller en Psicología, perteneciente a la Universidad San Ignacio de Loyola.

Este estudio se realizará en estudiantes universitarios peruanos que se encuentren cursando desde el 3er ciclo universitario hasta el 8vo con la finalidad de identificar cuánto influye la procrastinación académica sobre el cansancio emocional. Por ello, su participación es primordial en este proceso y estaremos agradecidos si accede.

La duración de toda la evaluación no será mayor a 10 minutos. Se solicitarán datos personales (nombre, edad, etc.) así como la respuesta a encuestas que valoran aspectos psicológicos (p.e., procrastinación académica). La información recopilada se tratará en forma confidencial y se enviarán los resultados pertenecientes a cada correo de manera personal. Toda la información se usará para fines del estudio y sin ningún otro propósito.

El proceso es completamente voluntario y puede interrumpir su participación cuando lo considere pertinente.

Si desea más información del proyecto, puede enviar un mensaje a krystel.lopez@usil.pe

En ese sentido, si usted está de acuerdo en participar, puede dar click al botón SIGUIENTE. 


\begin{tabular}{|c|c|}
\hline $\begin{array}{l}\text { 1. 2. Sexo: } \\
\square \text { Masculino } \\
\square \text { Femenino }\end{array}$ & 8-Ciclo/semetres académico \\
\hline 2. Edad: & $\begin{array}{l}\text { 9. ¿En cuántos cursos te has matriculado } \\
\text { este ciclo?? }\end{array}$ \\
\hline $\begin{array}{l}\text { 3. Estado civil } \\
\square \text { Soltero (a) } \\
\square \text { Casado (a) } \\
\square \text { Divorciado (a) } \\
\square \text { Viudo (a) }\end{array}$ & $\begin{array}{l}\text { 10. ¿La carrera que cursas actualmente } \\
\text { es tu primera carrera profesional? } \\
\square \text { Sí: } \\
\square \text { No }\end{array}$ \\
\hline 4. Número de hijos: & $\begin{array}{l}\text { 11. ¿En los últimos } 12 \text { meses académicos } \\
\text { cuántos cursos has desaprobado? }\end{array}$ \\
\hline $\begin{array}{l}\text { 5. Trabaja actualmente } \\
\square \text { Sí } \\
\square \text { No }\end{array}$ & $\begin{array}{l}\text { 12. ¿Te encuentras estudiando fuera de } \\
\text { Lima? } \\
\square \text { Sí } \\
\square \text { No }\end{array}$ \\
\hline $\begin{array}{l}\text { 6. Lugar de Nacimiento } \\
\square \text { Lima } \\
\square \text { Fuera de Lima }\end{array}$ & $\begin{array}{l}\text { 13. ¿Eres estudiante de traslado externo? } \\
\square \text { Sí } \\
\square \text { No }\end{array}$ \\
\hline 7. Carrera: & \\
\hline
\end{tabular}


Anexo 2:

\section{Procrastinación Académica (PA)}

Cuestionario 2. A continuación encontrarás una serie de preguntas que hacen referencia a tu modo de estudiar. Lee cada frase y contesta según tus últimos 12 meses de tu vida como estudiante marcando con una $\mathrm{X}$ de acuerdo con la siguiente escala de valoración:

\section{$\mathrm{N}=$ Nunca $\quad \mathrm{CN}=$ Casi Nunca $\quad \mathrm{AV}=\mathrm{A}$ veces $\mathrm{CS}=$ Casi siempre $\mathrm{S}=$ Siempre}

\begin{tabular}{|c|c|c|c|c|c|}
\hline \multirow{2}{*}{$\begin{array}{l}\text { 1. Cuando tengo que hacer una tarea, normalmente la dejo para el último } \\
\text { minuto. }\end{array}$} & $\mathrm{N}$ & $\mathrm{CN}$ & $\mathrm{AV}$ & $\mathrm{CS}$ & $S$ \\
\hline & & & & & \\
\hline 2. Generalmente me preparo por adelantado para los exámenes. & & & & & \\
\hline $\begin{array}{l}\text { 3. Cuando tengo problemas para entender algo, inmediatamente trato de } \\
\text { buscar ayuda. }\end{array}$ & & & & & \\
\hline 4. Asisto regularmente a clase. & & & & & \\
\hline 5. Trato de completar el trabajo asignado lo más pronto posible. & & & & & \\
\hline 6. Postergo los trabajos de los cursos que no me gustan. & & & & & \\
\hline 7. Postergo las lecturas de los cursos que no me gustan. & & & & & \\
\hline 8. Constantemente intento mejorar mis hábitos de estudio. & & & & & \\
\hline $\begin{array}{l}\text { 9. Invierto el tiempo necesario en estudiar aún cuando el tema sea } \\
\text { aburrido. }\end{array}$ & & & & & \\
\hline 10. Trato de motivarme para mantener mi ritmo de estudio. & & & & & \\
\hline 11. Trato de terminar mis trabajos importantes con tiempo de sobra. & & & & & \\
\hline 12. Me tomo el tiempo de revisar mis tareas antes de entr & & & & & \\
\hline
\end{tabular}


Anexo 3:

\section{Cansancio Emocional (ECE)}

Cuestionario 1. A continuación encontrarás una serie de preguntas que hacen referencia a tu modo de pensar, sentir y actuar respecto a tus estudios. Lee cada frase y contesta según tus últimos 12 meses de tu vida como estudiante marcando con una $\mathrm{X}$ de acuerdo con la siguiente escala de valoración:

\section{$\mathrm{RV}=$ Raras veces $\mathrm{PV}=\mathrm{Pocas}$ veces $\mathrm{AV}=\mathrm{Algunas}$ veces $\mathrm{CF}=\mathrm{Con}$ frecuencia $\mathrm{S}=$ Siempre}

\begin{tabular}{|l|l|l|l|l|l|}
\hline 1. Los exámenes me producen una tensión excesiva. & RV & PV & AV & CF & S \\
\hline 2. Creo que me esfuerzo mucho para lo poco que consigo. & & & & & \\
\hline 3. Me siento bajo de ánimo, como triste, sin motivo aparente. & & & & & \\
\hline 4. Hay días que no duermo bien a causa del estudio. & & & & & \\
\hline $\begin{array}{l}\text { 5. Tengo dolor de cabeza y otras molestias que afectan a mi } \\
\text { rendimiento académico. }\end{array}$ & & & & \\
\hline $\begin{array}{l}\text { 6. Hay días que noto más la fatiga y me falta energía para } \\
\text { concentrarme. }\end{array}$ & & & & \\
\hline 7. Me siento emocionalmente agotado por mis estudios. & & & & \\
\hline 8. Me siento cansado al final de la jornada de estudio. & & & & \\
\hline 9. Estudiar pensando en los exámenes me produce estrés. & & & & \\
\hline 10. Me falta tiempo y me siento desbordado por los estudios. & & & & & \\
\hline
\end{tabular}

